\title{
A Study on the Sintering of Ultrafine Grained Tungsten with Ti-Based Additives
}

Chai Ren ${ }^{1}$, Mark Koopman ${ }^{1}$, Z. Zak Fang ${ }^{* 1}$, Huan Zhang ${ }^{1}$, Brian van Devener ${ }^{2}$

1. Department of Metallurgical Engineering, University of Utah, 135 S. 1460 E. Rm 412, Salt Lake City, UT84112, United States

2.Utah NanoFab, University of Utah, 36 S. Wasatch Drive Rm 2500, Salt Lake City, UT84112, United States

\begin{abstract}
Tungsten (W) is a brittle material at room temperature making it very difficult to fabricate. Although the lack of ductility remains a difficult challenge, nano-sized and ultrafine grain (UFG) microstructures offer potential for overcoming tungsten's room temperature brittleness. One way to manufacture UFG W is to compact and sinter nanosized $\mathrm{W}$ powder, however, it is a non-trivial task to control grain growth during sintering. In an effort to inhibit grain growth, the effect of Ti-based additives on the densification and grain growth of nano-W powders was investigated in this study. The addition of $1 \mathrm{wt} . \% \mathrm{Ti}$ into tungsten led to more than a $63 \%$ decrease in average grain size of sintered samples at comparable density levels. It was also found that sintering in $\mathrm{Ar}$ yielded a finer grain size than sintering in $\mathrm{H}_{2}$ at similar densities. Compared to conventional high temperature sintering, a lower temperature sintering cycle for a longer hold time resulted in both near-full density and fine grain size. The roles of the $\mathrm{Ti}$ additive include not only the inhibition of grain growth, but also the potential absorption of oxygen from W particles.
\end{abstract}

Keywords: Nanocrystalline Material, Tungsten, Titanium, Sintering, Grain Growth, Ultrafine Grain

\section{Introduction}

Tungsten is a remarkable structural metal, and is used in a range of demanding environments and applications, such as light bulb filaments, heating elements and turbine components. Tungsten is also the principle proposed material for plasma facing components in fusion reactors [1-2]. However, issues with brittleness at room temperature along with a high ductile-brittle transition temperature (DBTT) cause serious reservations concerning its use in fusion reactors and restrict its use in other demanding applications [3-4]. In addition, tungsten recrystallizes at temperatures much lower than its melting point, a microstructural effect that tends to cause intergranular brittleness [5]. The development of tungsten alloys with improved mechanical properties, particularly at elevated temperatures, is important to several industries, and in terms of fusion reactor applications, could have profound consequences for society at large.

The development of tungsten alloys with very small grains, ultrafine-grains or nano-grains, has been approached as a route to improve the ductility and decrease the DBTT, since the large fraction of grain boundaries in the ultrafine-grained microstructure could shift the deformation mechanism [6]. Y. 
Kitsunai et al. demonstrated a significant decrease of the DBTT in ultrafine grained tungsten with an average grain size of $0.44 \mu \mathrm{m}$ [7]. Other BCC metals, including Al and Mo, have been shown to exhibit improvements in ductility and DBTT by forming nanocrystalline structures [8-9]. In ultrafine grained materials the increased grain boundary area has been seen to decrease the impurity concentration at grain boundaries [10-11]. In the case of tungsten, a decrease in grain boundary impurities could lead to improved strength and toughness.

In order to manufacture ultrafine grained tungsten, two general methods have been investigated: the top-down and the bottom-up approaches [11]. Severe plastic deformation (SPD) based techniques are the most often used top-down approach, and have shown improvement in the strength and toughness of tungsten [12-14]. However, this approach is often impractical from a manufacturing perspective due to problematic scale-up combined with the fact that this approach cannot be used to fabricate shapes with complex geometries. Alternately, the bottom-up approach involves the synthesis of nano-W powders, compaction of the nano powder, and a powder metallurgy (PM) approach involves compaction and sintering of powders. The control of grain growth during sintering is the greatest obstacle in the bottom-up PM method. Sintering $\mathrm{W}$ of more conventional grain sizes employs temperatures above $2,000 \mathrm{C}$, and the grain size of tungsten can reach $18 \mu \mathrm{m}$, or greater, with a sintered density less than 95\% [15].

Several authors have investigated other techniques, such as hot isostatic pressing (HIP), microwave sintering or spark plasma sintering (SPS), in order to obtain ultrafine-grained tungsten via the bottom-up approach [16-18]. A study by $\mathrm{M}$. Monge et al. reported the consolidation of pure $\mathrm{W}$ with an average grain size of $4.4 \mu \mathrm{m}$ by using a HIPing technique, and obtained a relative density of $92.7 \%$ [16]. Another research group obtained an average grain size of $3.2 \mu \mathrm{m}$ using microwave sintering of pure $\mathrm{W}$, but with a relative density of $96.9 \%$ [19]. Homogeneous dispersion of thermally stable particles, like $\mathrm{La}_{2} \mathrm{O}_{3}$ and $\mathrm{Y}_{2} \mathrm{O}_{3}$, have been used in $\mathrm{W}$ microstructures as an effective means to retain fine $\mathrm{W}$ grain size by inhibiting grain boundary migration during sintering $[10,19]$. Y. Kim et al. reported near fully dense $\mathrm{W}-5 \% \mathrm{Y}_{2} \mathrm{O}_{3}$ with an average grain size of $3.7 \mu \mathrm{m}$ by spark plasma sintering at $1700 \mathrm{C}$ [20]. The addition of $5 \mathrm{wt} . \%$ $\mathrm{Y}_{2} \mathrm{O}_{3}$ to tungsten, however, reduced the theoretical density from $19.25 \mathrm{~g} / \mathrm{cm}^{3}$ to less than $16.85 \mathrm{~g} / \mathrm{cm}^{3}$. Another research team has successfully produced $\mathrm{W}-1 \% \mathrm{Y}_{2} \mathrm{O}_{3}$ samples with $99 \%$ density and an average grain size of $3.2 \mu \mathrm{m}$ by spark plasma sintering at $1800 \mathrm{C}$ [21]. The grain size obtained, $3.2 \mu \mathrm{m}$, is much larger than the ultrafine grain range, which is generally defined as less than $500 \mathrm{~nm}$. The manufacture of near fully dense tungsten material with high density and ultrafine grain size remains a technical challenge.

Titanium carbide, $\mathrm{TiC}$, another thermally stable particle has also been used to inhibit grain growth in tungsten. As reported by X. Ding et al., spark plasma sintering of $\mathrm{W}-1 \%$ TiC produced an average grain size of $3 \mu \mathrm{m}$ and relative density of $98.6 \%$ [22]. Additionally, S. Lang et al. demonstrated a decrease in tungsten's DBTT to below $300^{\circ} \mathrm{C}$ on samples that had undergone hot rolling with an $83 \%$ reduction ratio of sintered W-TiC alloy [23]. Theoretical and experimental research on the alloying of tungsten with $\mathrm{Ti}$ metal, as well as work on other Ti compounds, have also shown sufficient cause for further investigation. First principles simulations performed by D. Jiang suggested the ductility of bcc $W$ could be improved by the addition of $\mathrm{Ti}$ [24]. Research on $\mathrm{W}$-Ti oxide dispersion strengthened alloys with low $\mathrm{Ti}$ additive compositions by $\mathrm{C}$. Chen et al., showed uniform microstructures, but as the content of Ti increases to $10 \%$, the microstructure becomes non-uniform [25]. And, S. Wang et al. reported on the spark plasma sintering of a TiN reinforced W-Ti alloy, which reached a very high density with a $0.62 \mu \mathrm{m}$ average grain 
size using a Ti composition of 4\% [26]. Despite these diverse and promising Ti alloy studies, the effect of Ti additives on tungsten sintering is still lacking.

Many researchers have predicted the difficulty of consolidating nano tungsten powders to achieve full density, while maintaining ultrafine grain size. It has generally been held that ultrahigh compaction pressure and very low sintering temperature are necessary $[27,28]$. In contrast, however, research by Wang et al. showed it is possible to sinter nano-W powders to near-full density at relatively low sintering temperatures, using pressureless sintering techniques $[29,30]$. The potential of using additive dispersion to further assist in producing fine grain size using the pressureless low temperature sintering of nano-W powders was deemed advantageous.

In the present work, a detailed investigation was undertaken of the low temperature pressureless sintering of milled nano-W powders with Ti-based additives. The effect of Ti-based additives on the grain growth of nano-W is presented, and a method to further minimize final grain sizes by adjusting sintering process parameters is discussed. The ultimate goal of this work is to manufacture ultrafine-grained tungsten by using a conventional pressureless sintering process, through optimizing processing parameters, including the use of nano-sized $\mathrm{W}$ powder, low sintering temperatures, and the use of Ti as a grain growth inhibitor.

\section{Experimental Procedure}

Feedstock materials were procured from commercial vendors, and included: tungsten, titanium hydride and titanium carbide powders. The tungsten powders had an average particle size of approximately $50 \mathrm{~nm}$, and the $\mathrm{Ti}$ and $\mathrm{TiC}$ powders each were approximately $44 \mu \mathrm{m}$. The powders were further milled using a custom designed high-energy planetary ball mill (HEPM) [31] for $6 \mathrm{~h}$ in a mixture of heptane and ethanol. The ball to powder ratio was 5:1. The $60 \mathrm{~g}$-force acceleration field generated during the planetary ball milling effectively reduced the tungsten and Ti powders to the nano-scale. The average grain size of milled powders was characterized as $17 \mathrm{~nm}$ using an $\mathrm{x}$-ray diffraction line broadening technique. Details of the milling process have been described previously [32].

Green parts were formed from the milled W-Ti powders by compacting into $16 \mathrm{~mm}$ diameter cylinders using a uniaxial die press with $54 \mathrm{MPa}$ pressure and a $5 \mathrm{~min}$ hold time. The average green density was measured at $6.29 \mathrm{~g} / \mathrm{cm}^{3}$, which is approximately $34 \%$ of the relative density. The reduction and sintering processes of the compacted green parts were performed using an atmosphere controlled tube furnace. All samples were reduced at $700{ }^{\circ} \mathrm{C}$ for $3 \mathrm{~h}$ with flowing $\mathrm{H}_{2}$ to remove the oxide that formed on tungsten powders during the milling and drying processes. After reduction, the samples were sintered at 1000 to $1300{ }^{\circ} \mathrm{C}$ for 1 to $16 \mathrm{~h}$ in either flowing $\mathrm{Ar}$ or $\mathrm{H}_{2}$ to study the effects of sintering temperature, atmosphere, and time on the grain coarsening and densification behaviors of the nano-WTi powders.

The Archimedes method was used to measure the density of sintered samples. Samples were then mounted in epoxy resin and polished using diamond suspensions to a $0.25 \mu \mathrm{m}$ surface finish. Grain size measurements were made from SEM micrographs of polished surfaces using a strong backscattered component that revealed grain orientation contrast. Average grain sizes were determined using the linear intercept method. At least 400 intercepts of grains were measured from at least 5 randomly 
selected SEM images for each sample. The average grain sizes were calculated based on the lengths of these intercepts. To study the chemical states of tungsten and titanium of the sintered $\mathrm{W}-1 \% \mathrm{Ti}$ samples, samples were fractured using a hand-held sheer cutter inside a glove box under Ar atmosphere, in order to obtain fresh fracture surfaces without oxidation. These samples were transferred into a Kratos Axis Ultra x-ray photoelectron spectroscopy (XPS) system, using an atmosphere controlled stage, and XPS spectra were taken on the fresh fracture surfaces. Subsequently, fracture surfaces of sintered samples were characterized using an FEI NovaNano scanning electron microscope (SEM), and the chemical compositions of different phases were analyzed using the energy-dispersive X-ray spectroscopy (EDS) method. TEM samples were fabricated by the focused ion beam technique, and analyzed in a JEOL JEM2800 equipped with EDS and dual tilt stage. The bulk oxygen contents of sintered samples were characterized using a LECO TCH600 N/O/H determinator.

\section{Results and Discussion}

\subsection{Effects of the Ti Additive on Sintering of Nano-W Powders}

To study the effects of $\mathrm{Ti}$ additions on grain growth and densification, a range of compositions was investigated, alloying nano-W with $0-3$ wt.\% of either TiC or Ti. Regarding Ti, titanium hydride was the initial feedstock, but the hydrogen disassociates during heating to the reduction/sintering temperatures. $\mathrm{TiH} 2$ is not stable at high temperature, and Ar, of course, is inert, so little difference would be anticipated between the two atmospheres. Figure 1 shows the change of relative sintering density as a function of additive composition for the nano-W powder prepared using HEPM processing with Ti or TiC. Samples of Figure 1 and 2 were sintered first at $1050^{\circ} \mathrm{C}$ for $2 \mathrm{~h}$ and then at $1300^{\circ} \mathrm{C}$ for $1 \mathrm{~h}$ in hydrogen atmosphere. The sintering density of nano-W powders decreases as the Ti or TiC composition increases, and a $3 \mathrm{wt} . \%$ addition of TiC leads to approximately a $20 \%$ decrease in the relative density. Compared to $\mathrm{TiC}$, the $\mathrm{Ti}$ additive leads to a much more gradual decrease in sintered density as the additive composition increases, and is able to reach $94 \%$ relative density with a composition of $3 \mathrm{wt} . \%$.

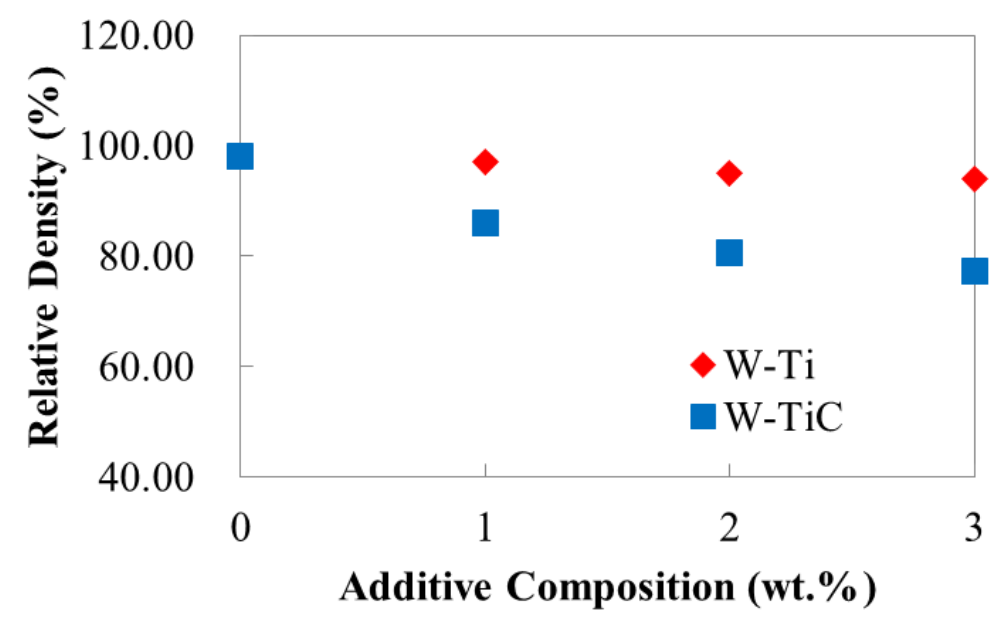

Figure 1 Effects of $\mathrm{Ti}$ and TiC composition on the relative sintering density of HEPM milled nano-W powders. 
The key objective of adding Ti to UFG or nano-W in the present work is to reduce grain growth during sintering through grain boundary pinning. Figure 2 shows a grain size vs. relative density plot of nano-W powders with 0 to $3 \mathrm{wt}$.\% Ti. The $1 \mathrm{wt} . \%$ Ti addition led to a dramatic decrease in the average grain size of sintered nano-W powders from 1,572 nm to $577 \mathrm{~nm}$. Further increases in Ti composition up to $3 \mathrm{wt} . \%$ led to no significant change in the average grain size. However, the addition of $\mathrm{Ti}$ also decreased sintered density under the same sintering conditions, and increasing Ti content showed decreasing final density. These results indicate that the addition of $\mathrm{Ti}$ inhibits both grain growth and densification during the sintering process. Comparing the relative density and grain size results, the $\mathrm{Ti}$ addition reached its maximum effect as a grain growth inhibitor at, or below, 1 wt.\%, but its effect on impeding densification continued to increase as the Ti composition increased. Larger amounts of the $\mathrm{Ti}$ additive, with its lower density, also led to significant decreases in the theoretical density of the nano-W material, which is undesired for many applications. Therefore, $\mathrm{W}$ with $1 \mathrm{wt} . \%$ Ti additive was the optimal composition within the parameters of this study, providing refined grain size with relatively high sintering density. The remainder of this study focuses solely on the addition of Ti.

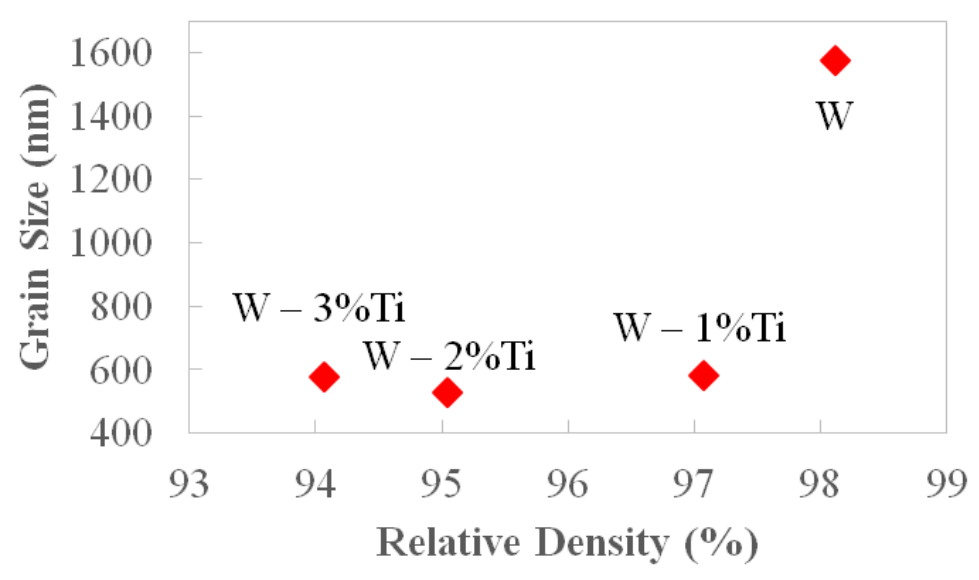

Figure 2 Grain size vs. relative sintered density of nano-W powder with different Ti additive compositions.

\subsection{Effect of Temperature and Atmosphere on Sintering of Nano-W Powder with Ti Additive}

Sintering was performed in either argon or hydrogen environments to examine potential differences in sintering kinetics. Figure 3 compares the relative density change as a function of sintering temperature with $\mathrm{H}_{2}$ or Ar atmosphere for the nano-W powders with $1 \% \mathrm{Ti}$. In both atmospheres, the sintering density of the $\mathrm{W}-1 \% \mathrm{Ti}$ samples increases as the sintering temperature increases. In the hydrogen atmosphere, $\mathrm{W}-1 \% \mathrm{Ti}$ samples sintered at $1000^{\circ} \mathrm{C}$ for $1 \mathrm{~h}$ showed limited densification, and only marginally exceeded $90 \%$ density at 1100 and $1200{ }^{\circ} \mathrm{C}$. The maximum density for the $\mathrm{H}_{2}$ atmosphere was $93.95 \%$, which resulted from sintering at $1300{ }^{\circ} \mathrm{C}$ for $1 \mathrm{~h}$. Sintering $\mathrm{W}-1 \% \mathrm{Ti}$ in an $\mathrm{Ar}$ atmosphere led to improved densification; a relative density of $92 \%$ was reached with a temperature as low as $1100{ }^{\circ} \mathrm{C}$. The highest density of $98.28 \%$ was obtained by sintering at $1300^{\circ} \mathrm{C}$ for $1 \mathrm{~h}$. As reported in earlier work, this low temperature sintering approach is only achievable by using nano-sized tungsten powders [32]. The better densification in Ar atmosphere is likely due to enhanced bulk-diffusion and limited vapor transportation, as $\mathrm{WO}_{2}(\mathrm{OH})_{2}$ may be minimized during sintering [32]. 


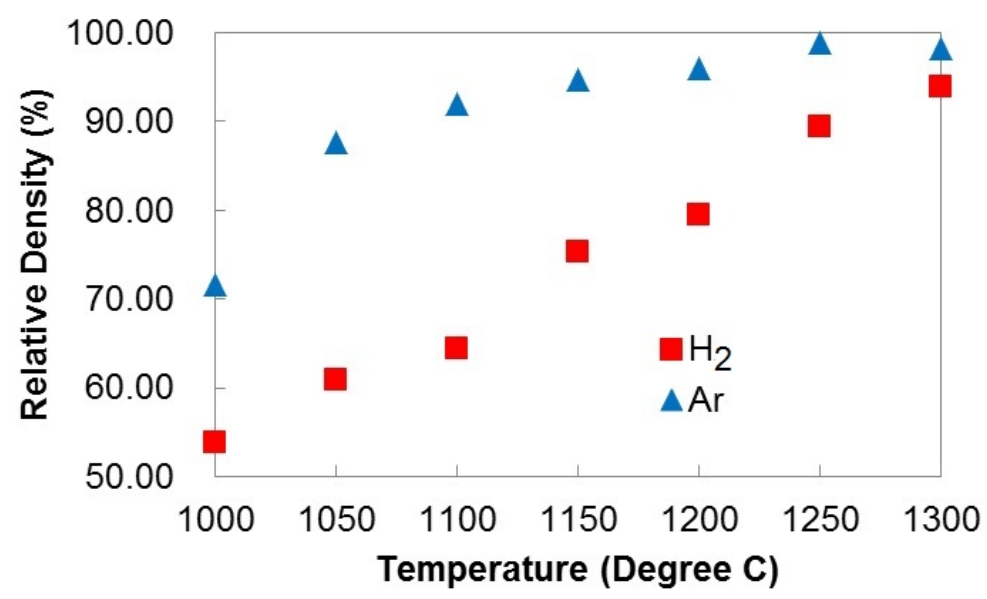

Figure 3 Effect of temperature and atmosphere on the relative sintering density of nano-W powders with 1 wt.\% Ti.

To augment data measurements on densification and grain growth of nano-W powders with $\mathrm{Ti}$ alloying, microstructures of $\mathrm{W}-1 \% \mathrm{Ti}$ samples were examined that had been sintered with $\mathrm{H}_{2}$ and $\mathrm{Ar}$ atmospheres across a range of temperatures. SEM images of the surfaces of $\mathrm{W}-1 \% \mathrm{Ti}$ samples that were fractured by impact are shown in Fig. 4. The $\mathrm{W}-1 \%$ Ti powders sintered at $1000{ }^{\circ} \mathrm{C}$ in $\mathrm{H}_{2}$, Fig. $4 \mathrm{a}$, showed the least densification of the samples examined. The fracture surface is very similar to a compacted green part, with only slightly larger particle size and a smoother surface. Compared to the sample sintered at $1000{ }^{\circ} \mathrm{C}$, the samples sintered at 1100 and $1200{ }^{\circ} \mathrm{C}$ in $\mathrm{H}_{2}$ exhibited bonding, which began to form between particles, and some grains showed a polyhedral morphology. There is still significant porosity, but some channels are divided into smaller segments, and open porosity appears to be diminished. Samples sintered at $1300{ }^{\circ} \mathrm{C}$ for $1 \mathrm{~h}$ in $\mathrm{H}_{2}$ showed a more consistent polyhedral morphology, Fig. 4d, with fewer interconnected pores. This corresponds to an intermediate to final stage of sintering.

In contrast to samples sintered in a $\mathrm{H}_{2}$ atmosphere, $\mathrm{W}-1 \%$ Ti samples sintered in Ar had much lower porosity, combined with $\mathrm{W}$ grains that exhibited a more classically polyhedral shape. The microstructure of a sample sintered at $1000{ }^{\circ} \mathrm{C}$ in Ar, Fig. 4e, begins to show the formation of bonds between grains. Sintering at $1100{ }^{\circ} \mathrm{C}$ and above exhibited a clear increase in grain size, along with isolated spheroidal pores, which corresponds to the final stage of sintering. As sintering temperature was increased, improved densification was observed along with increased grain size, and a small number of spherical pores can still be observed at grain boundaries even when sintered at $1300^{\circ} \mathrm{C}$. This analysis of the sintered microstructures is consistent with the reported density results, since at equivalent temperature, sintering in $\mathrm{Ar}$ always resulted in better densification than sintering in $\mathrm{H}_{2}$. While $1300{ }^{\circ} \mathrm{C}$ was necessary for the $\mathrm{H}_{2}$ sintered sample to reach greater than $90 \%$ density, the Ar sintered samples reached $92 \%$ relative density at only $1100{ }^{\circ} \mathrm{C}$. 

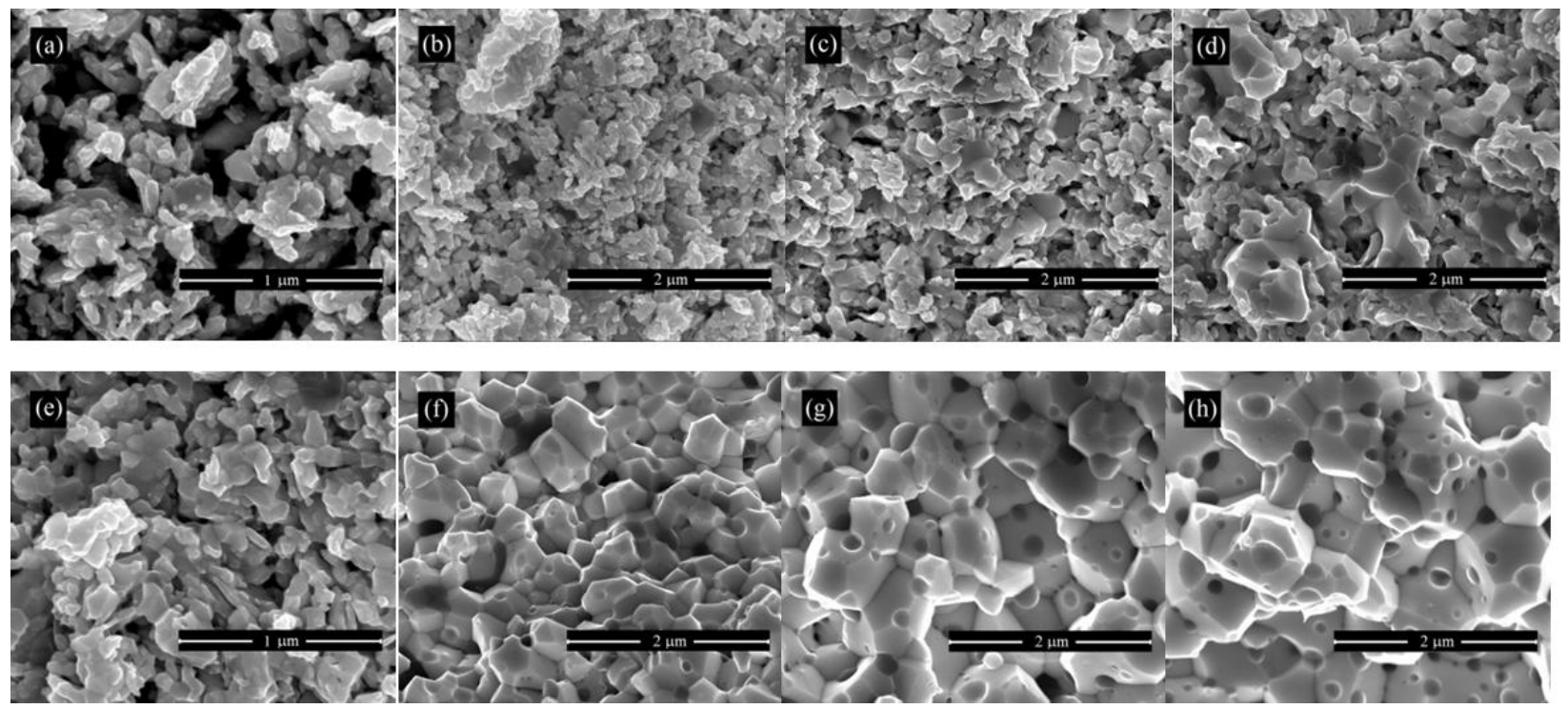

Figure 4 SEM fracture surfaces of sintered nano-W with 1 wt.\% Ti additive at: (a) $1000{ }^{\circ} \mathrm{C}$ in $\mathrm{H}_{2}$, (b) $1100{ }^{\circ} \mathrm{C}$ in $\mathrm{H}_{2}$, (c) $1200{ }^{\circ} \mathrm{C}$ in $\mathrm{H}_{2}$, (d) $1300{ }^{\circ} \mathrm{C}$ in $\mathrm{H}_{2}$, (e) $1000{ }^{\circ} \mathrm{C}$ in $\mathrm{Ar}$, (f) $1100{ }^{\circ} \mathrm{C}$ in $\mathrm{Ar}$, (g) $1200{ }^{\circ} \mathrm{C}$ in $\mathrm{Ar}$ and (h) $1300{ }^{\circ} \mathrm{C}$ in $\mathrm{Ar}$.

The variation of average grain size, measured on polished cross sections, as a function of relative density for $\mathrm{W}-1 \% \mathrm{Ti}$ samples is given in Fig. 5. The average grain size increases as the sintering temperature and relative density increase (see also Fig. 3). The grain size of samples sintered in a $\mathrm{H}_{2}$ atmosphere increases gradually as the sintering temperature and relative density increase, and reaches $600 \mathrm{~nm}$ at $1300{ }^{\circ} \mathrm{C}$ with $93.95 \%$ relative density. Similarly, the grain size of Ar atmosphere sintered samples also increases slowly as the sintering temperature increases up to $1100{ }^{\circ} \mathrm{C}$, and relative density reaches $92 \%$. However, for sintering temperatures above $1100{ }^{\circ} \mathrm{C}$ the improved density leads to rapid grain growth, and the average grain size reaches $1010 \mathrm{~nm}$ at $1300^{\circ} \mathrm{C}$. The rapid grain coarsening effect becomes active during the final stage of sintering. Within this data set, to reach an equivalent relative density, sintering in Ar always required much lower sintering temperature and led to a much finer grain size than sintering in $\mathrm{H}_{2}$.

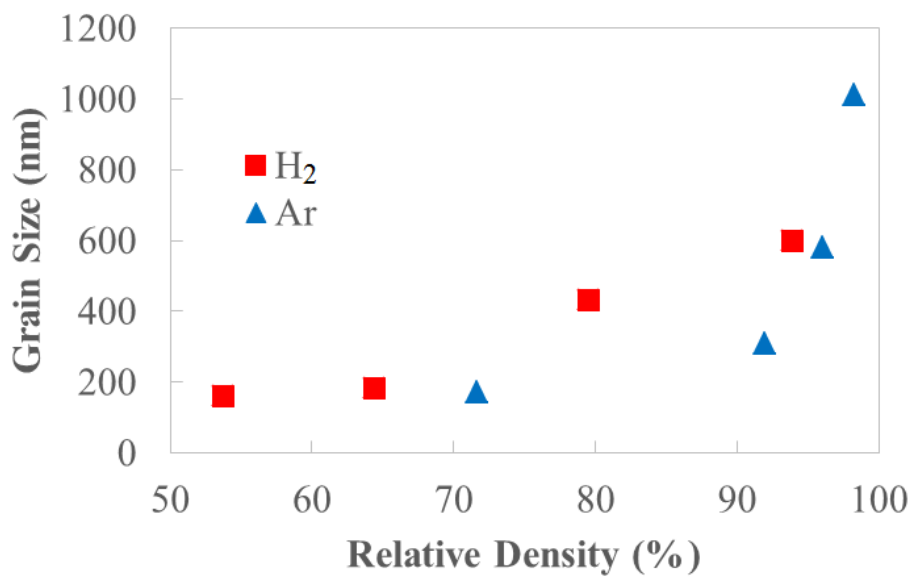

Figure $5 \mathrm{~W}$ grain size vs. relative density of nano-W powder with $1 \mathrm{wt} . \%$ Ti additive sintered at different temperatures and under argon or hydrogen atmospheres. 
The scaling law can be used to describe the relationship between grain size and sintering behavior for $\mathrm{W}$ powders sintered in $\mathrm{Ar}$ or $\mathrm{H}_{2}$ atmospheres, and is given by the following equation [33-35]:

$$
n \ln \left(\frac{d_{1}}{d_{2}}\right)=\frac{Q}{R}\left[\frac{1}{T_{2}}-\frac{1}{T_{1}}\right]
$$

Here, $d_{1}$ and $d_{2}$ are the grain sizes at two different sintering temperatures, $T_{1}$ and $T_{2}$ are those corresponding sintering temperatures, $\mathrm{Q}$ is the activation energy, and $\mathrm{R}$ is the ideal gas constant (8.314 $\mathrm{J} / \mathrm{mol}^{*} \mathrm{k}$ ). The constant, $\mathrm{n}$, is an exponent dependent on active diffusion mechanisms; where $\mathrm{n}=0.67$ for vapor transport, $n=0.5$ for volume diffusion and $n=0.33$ for grain boundary diffusion. German et al. [36] calculated the $Q / R$ value of tungsten sintering, and using empirical evidence reported it to be $4407 \mathrm{~K}$. Based on previous studies and data obtained in this work, the relationships between sintering temperature and grain size in $\mathrm{Ar}$ and $\mathrm{H}_{2}$ atmospheres were examined, Fig. 6 (a) and (b). Figure 6 (a) shows the sintering behavior of nano-W powders with $\mathrm{Ti}$ in an Ar atmosphere, falling between the curves for volume diffusion and grain boundary diffusion. A best-fit curve provides an excellent match to the experimental data with an $\mathrm{n}$ value equal to 0.38 . In this case, all samples sintered quickly to greater than $90 \%$ relative density, Fig. 3, thus allowing easy comparison of the data in terms of grain size analysis. Therefore, the dominant mechanism for densification in the sintering of nano-W powder with $\mathrm{Ti}$ in an Ar atmosphere is likely a mixture of volume diffusion and grain boundary diffusion.

As opposed to sintering in $\mathrm{Ar}$, sintering in an $\mathrm{H}_{2}$ atmosphere led to a more complex behavior. Figure 6 (b) shows that in the low temperature range, the data matches well with the calculated curve for vapor transport. With increasing temperature, the experimental results begin to shift, and obtain an excellent fit with the calculated volume diffusion curve for temperatures above $1200^{\circ} \mathrm{C}$. This result is consistent with our previously reported research, where in a $\mathrm{H}_{2}$ atmosphere, tungsten experienced chemical vapor transport as a result of the volatile $\mathrm{WO}_{2}(\mathrm{OH})_{2}$ phase [32]. At higher sintering temperatures, the efficient reduction of $\mathrm{WO}_{2}$ results, and $\mathrm{WO}_{2}(\mathrm{OH})_{2}$ is not as prevalent. The disparity in fit of the data in Fig. 6(b) may be due to differences observed in densification rate across the tested temperature range.

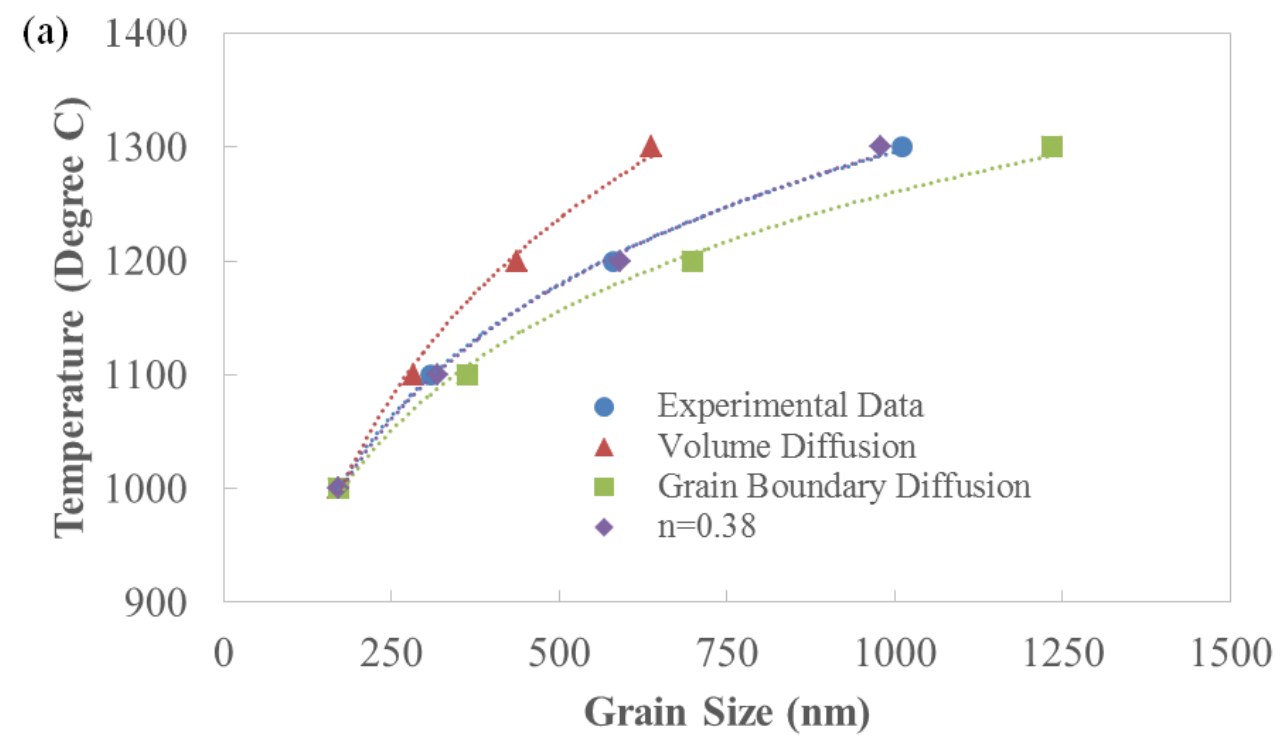




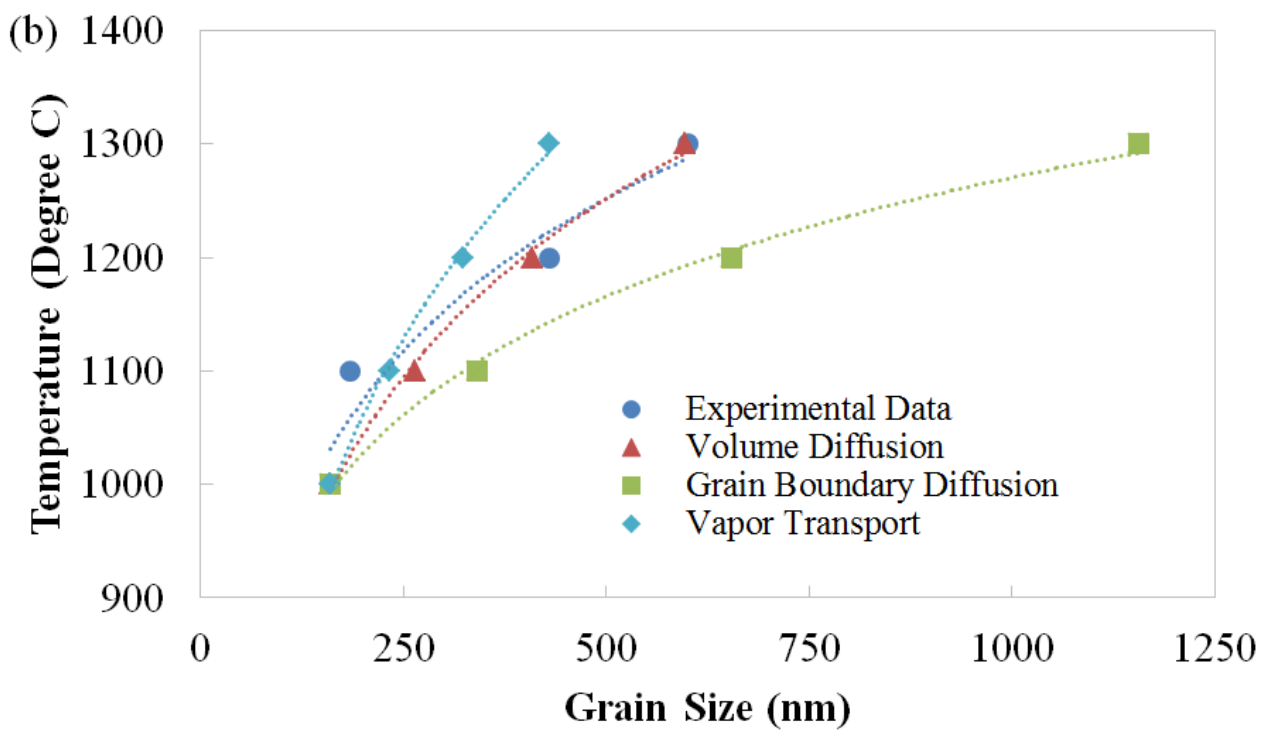

Figure 6 Relationship of sintering temperature and grain size descried by the scaling law for nano-W with 1 wt.\% Ti sintered in an (a) Ar and (b) $\mathrm{H}_{2}$ atmosphere.

\subsection{Effect of Time on Sintering of Nano-W Powders}

As discussed in the previous section, in order to avoid the rapid grain coarsening caused by high temperature sintering, a relatively low sintering temperature, near $1100{ }^{\circ} \mathrm{C}$ or lower, is required. However, a $200{ }^{\circ} \mathrm{C}$ drop in sintering temperature leads to a significant decrease in densification kinetics. To obtain sintered $\mathrm{W}$ samples with high density and fine grain size in the present work, ultra long sintering times were employed to overcome the limitation of densification kinetics at low temperature. Nano-W powders with a $1 \% \mathrm{Ti}$ additive were sintered at $1100{ }^{\circ} \mathrm{C}$ in $\mathrm{Ar}$ atmosphere for times ranging from 1 to $16 \mathrm{~h}$, and Fig. 7 shows a plot of relative density vs. sintering time. Based on the figure, increasing the sintering time from 1 to $16 \mathrm{~h}$ leads to a substantial increase in sintering density, from $92.27 \%$ to $96.70 \%$. This density is comparable to the sintering density obtained from higher temperature sintering at 1200 to $1300{ }^{\circ} \mathrm{C}$. The rate of densification decreases as the sintering time and density increases, but nonetheless makes a significant improvement during the 8 to $16 \mathrm{~h}$ period. The average grain sizes of these low-temperature sintered samples were characterized using SEM, and the results are shown in Fig. 8. Generally, the grain size of sintered samples increased as the relative density increased. However, only $205 \mathrm{~nm}$ of growth was observed on the average grain size as the density increased from $92.27 \%$ to $96.7 \%$, which is much less than a comparable density result obtained by increasing the sintering temperature. Furthermore, no trend for rapid grain coarsening is observed on the plot even when the sintering density increases above $93 \%$, where grain growth was seen to rapidly increase in this system at higher temperatures. The result of this sintering cycle, using extended time at low temperature, demonstrates a potential approach to obtaining ultrafine grain sizes in tungsten with nearfull density, while maintaining limited grain growth. 


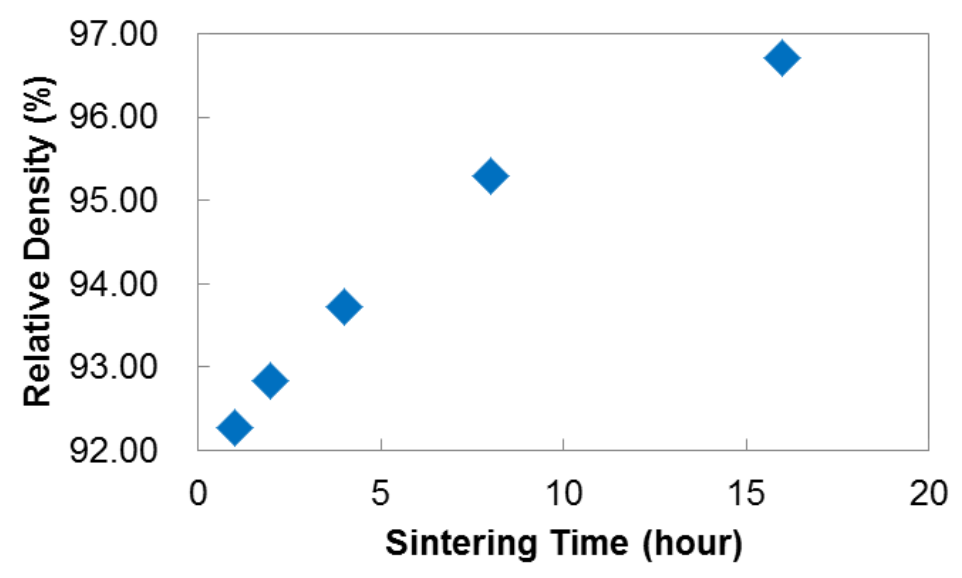

Figure 7 Relative density vs. sintering time of nano-W powders with Ti during sintering at $1100{ }^{\circ} \mathrm{C}$ in $\mathrm{Ar}$ atmosphere.

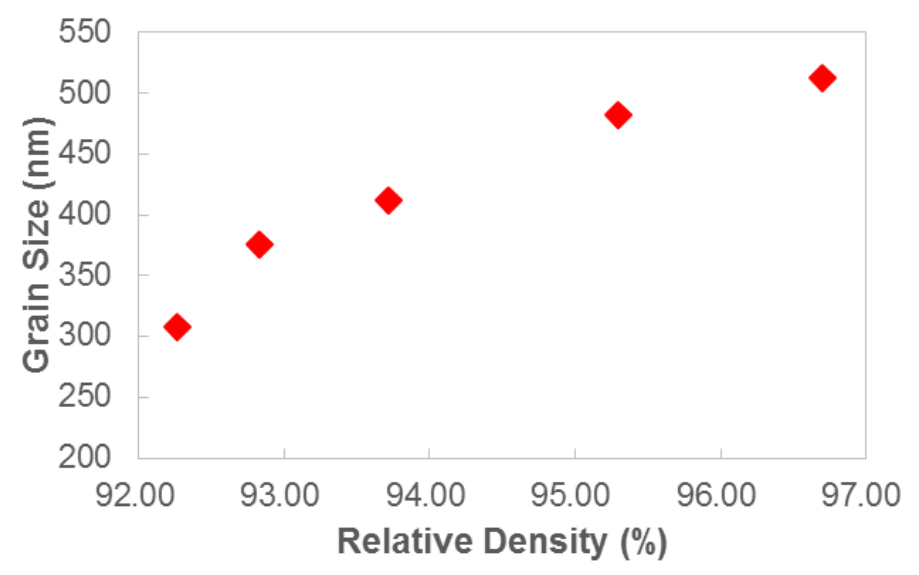

Figure $8 \mathrm{~W}$ grain size vs. relative density for $\mathrm{W}-1 \mathrm{wt} . \% \mathrm{Ti}$ samples sintered at $1100^{\circ} \mathrm{C}$ from 1 to $16 \mathrm{~h}$ in $\mathrm{Ar}$ atmosphere.

\subsection{Grain Growth Inhibition and Oxygen Absorption Effects}

Based on discussion above, the addition of $\mathrm{Ti}$ leads to a dramatic decrease in the average grain size of sintered nano-W powders over pure $\mathrm{W}$ samples. Figure 9 shows an SEM micrograph of the fracture surface of a W-1 wt.\% Ti sample sintered at $1300{ }^{\circ} \mathrm{C}$. The lighter gray phase is the sintered tungsten matrix, and the darker phase is the Ti rich second phase (note: some pull out of the latter phase can be observed). Intergranular fracture was dominant in this fracture surface, with cracks propagating principally along the grain boundaries and phase boundaries; so, the cohesive strength of these boundaries is much lower than that of the $\mathrm{W}$ grains. The Ti rich phase was homogeneously distributed in the tungsten samples, and was observed to primarily be located along grain boundaries in polished cross sections. The average grain size of the Ti particles was approximately $290 \mathrm{~nm}$ with a generally spherical shape, and the Ti grain size was much smaller than the $1010 \mathrm{~nm}$ average grain size for tungsten. It is known that well dispersed thermally stable oxide particles, like $\mathrm{Y}_{2} \mathrm{O}_{3}$, can hinder grain boundary migration and inhibit grain growth, which may improve strength and high temperature stability [18]. For 
W -1 wt.\% Ti material, the Ti may also work as a grain growth inhibitor in a similar manner, explaining the significant decrease seen in the average grain size in UFG tungsten with the addition of Ti.

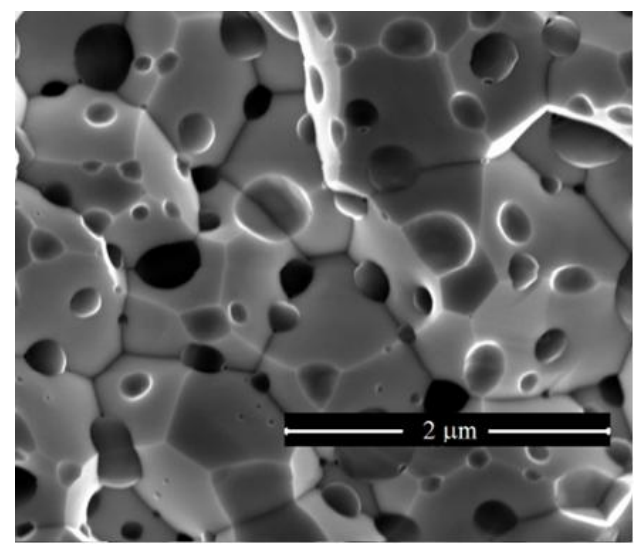

Figure 9 Fracture surface showing microstructure of $\mathrm{W}-1$ wt.\% Ti sample sintered at $1300{ }^{\circ} \mathrm{C}$ under $\mathrm{Ar}$ atmosphere.

To obtain more accurate information about the chemical states of Ti and $\mathrm{W}$ in sintered samples, XPS measurements were performed on a fresh fracture surface without exposure to oxygen. Figure 10 (a) and (b) show the spectra of Ti $2 p$ and $W 4 f$ peaks from the XPS analysis. The position of the primary $W$ peak is located at $31.3 \mathrm{eV}$, which is the typical energy range for metallic tungsten [37]. Taking the large energy difference between tungsten and tungsten oxide into consideration, the peak profiles of the $\mathrm{W}$ $4 \mathrm{f}$ peaks indicate this sample mainly contains tungsten in its metallic state. The position of Ti $2 p$ peaks are shifted toward a higher energy, and are located at $459 \mathrm{eV}$, which is the typical energy range for the $\mathrm{TiO}_{2}$ state [37]. No signal is observable at the $454 \mathrm{eV}$ position for metallic titanium. Therefore, the near surface of the Ti phase is essentially $\mathrm{TiO}_{2}$.
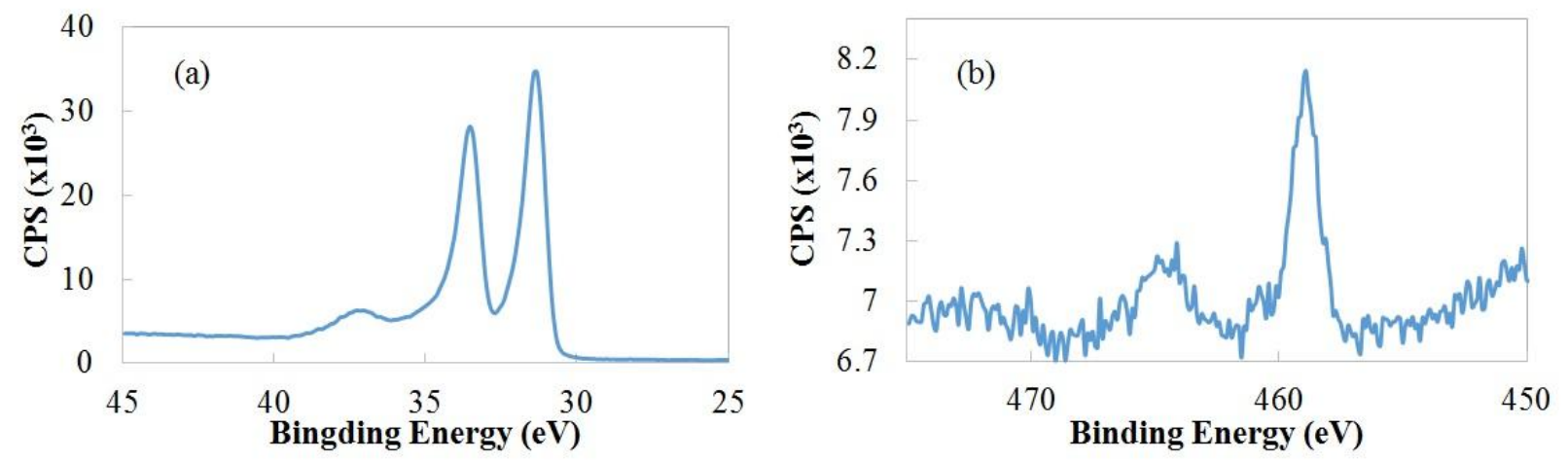

Figure 10 XPS analysis of fresh fracture surfaces of sintered ultrafine grained W-1 wt\% Ti sample. (a) W $4 f$ peaks and (b) Ti $2 p$ peaks.

There are two stages during processing where the Ti additive may become oxidized. This can occur during the milling and drying stage, where Ti may be exposed to oxygen in the air, or during the reduction and sintering stage, where $\mathrm{Ti}$ may function as a reducing agent for $\mathrm{W}$ oxide. To further understand the oxidation of $\mathrm{Ti}$ within the bulk of sintered samples, oxygen contents of the sintered samples were characterized using a LECO N/O/H determinator. Figure 11 compares the $\mathrm{O}$ content 
obtained in this manner with the theoretical estimated $\mathrm{O}$ contents for sintered $\mathrm{W}$ powders with different Ti compositions. The theoretical estimated $\mathrm{O}$ content is calculated based on the assumption of all $\mathrm{Ti}$ additives having been fully oxidized. Based on the figure, oxygen content increases linearly as the $\mathrm{Ti}$ composition increases. The experimental $O$ content is always less than the estimated $O$ content, which indicates partial oxidation of $\mathrm{Ti}$, with metallic Ti likely remaining at the core of these particles. If the $\mathrm{Ti}$ oxidation happens solely during the milling and drying processes, due to the abundant amount of $O$ in the air, all the Ti particles should be oxidized to the same saturated level. In this case, the ratio between experimental $\mathrm{O}$ and estimated $\mathrm{O}$ should be constant for all $\mathrm{Ti}$ compositions. However, this ratio decreases as the Ti composition increases, which is about 0.78 for $1 \% \mathrm{Ti}, 0.73$ for $2 \% \mathrm{Ti}$ and 0.69 for $3 \%$ $\mathrm{Ti}$. This indicates the involvement of the reduction/sintering processes in the Ti oxidation. The decrease of this ratio with increasing Ti content can be understood such that only a limited amount of the Ti need be oxidized as a reducing agent, and the percentage of Ti thus oxidized will decrease as the total amount of Ti additive increases. Alternately, the partial oxidation of the Ti phase may be the result of passivation or partial oxidation of near surface regions of any given Ti particle.

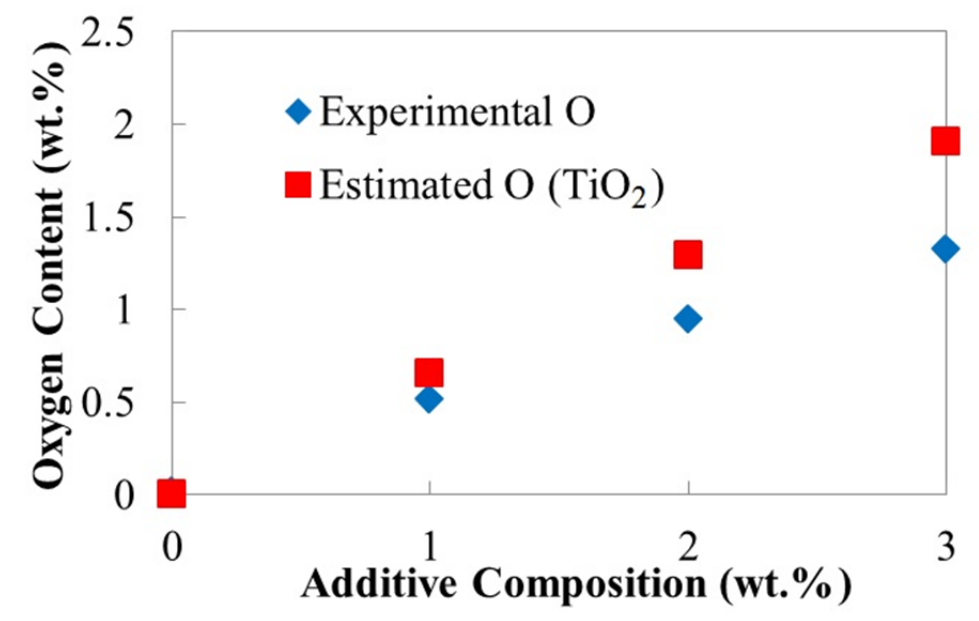

Figure 11 Comparison of experimental bulk $\mathrm{O}$ content measurements and estimated $\mathrm{O}$ content $\left(\right.$ full $\left.\mathrm{TiO}_{2}\right)$ of sintered nano-W powders with different Ti compositions.

Transmission electron microscopy (TEM) was used to gain further information on the Ti rich phase in the microstructure. Figure 12 shows a bright field micrograph of a typical Ti rich phase within the microstructure and very near the thin edge of the TEM foil. Qualitative EDS analyses of Ti rich particles showed the presence of minor amounts of $\mathrm{Cr}, \mathrm{V}$ and $\mathrm{Fe}$, which may have been scavenged from the milling container. Analysis by EDS of circular regions in Fig. 12, marked A and B, showed a profound difference in the titanium to oxygen contents of the two regions. Area $A$, presumably thicker given that it is further from the edge of the TEM foil, showed a ratio of the Ti K-alpha peak height to $\mathrm{O} K$-alpha peak height of $\sim 1.4$, while area $B$, the thinner region of the foil, showed a ratio of 0.89 . This data corroborates the XPS findings and oxygen content data of Fig. 11, and indicates that while the near surfaces oxidize readily, there is likely metallic Ti in the interior of these particles. 


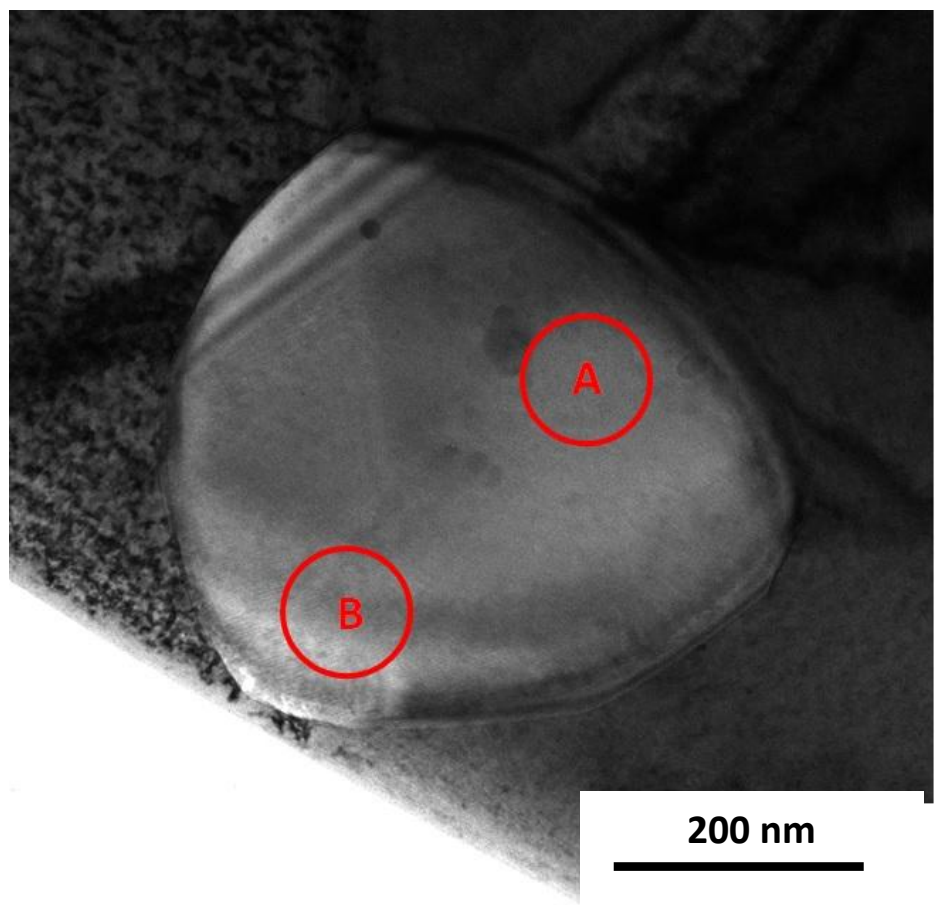

Figure 12 TEM bright field micrograph of a Ti rich phase in nano-W-1\%Ti

The Ti within bulk sintered $\mathrm{W}$ may not only functions as a grain growth inhibitor, but may also function as a reducing agent, absorbing oxygen from the surrounding $\mathrm{W}$ grains and grain boundaries during the reduction and sintering process. In addition to the reduction effect of the hydrogen atmosphere during processing, this oxygen absorption behavior may help to further reduce the oxygen level of the $\mathrm{W}$ grains and grain boundaries. Tungsten is known to be sensitive to oxygen contamination, as a minor amount of oxygen can increase the activation energy for surface diffusion during sintering [38], and oxygen segregating to grain boundaries can decrease the grain boundary cohesion [10]. Therefore, this oxygen absorption behavior of Ti may be particularly valuable, as it could improve both the sintering of $\mathrm{W}$ and also the strength and toughness of sintered materials.

\section{Conclusions}

Addition of minor amounts of $\mathrm{Ti}$ to the high energy planetary milled nano-tungsten powders inhibited the grain growth during sintering, and led to a dramatic decrease in the average grain size of sintered ultrafine-grained $\mathrm{W}$ samples. Compared to a $\mathrm{H}_{2}$ atmosphere, $\mathrm{W}-1 \%$ Ti nano-powders sintered in Ar showed improved densification with less grain growth. Long duration low temperature sintering was shown to be an effective method to obtain samples with near-full density and refined grain size, compared to higher temperature sintering. SEM and XPS studies showed that the Ti addition not only functioned as a grain growth inhibitor, but may also absorb oxygen from adjacent $\mathrm{W}$ grains or grain boundaries.

\section{Acknowledgements}

The Authors wish to thank the U.S. Department of Energy (DOE) (DESC0008673), Office of Science, Fusion Materials Program and the U.S. Department of Defense (DOD), SBIR program for financial support. This work made use of the University of Utah USTAR shared facilities supported, in part, by the 
MRSEC Program of NSF under Award No. DMR-1121252. The authors would also like to thank Mr. Randy Polson for fabrication of the TEM samples by focused ion beam, and Mr. Brady Butler from the Army Research Laboratory for many valuable discussions.

\section{Reference}

[1] J. W. Davisa, V. R. Barabashb, A. Makhankovc, L. Plochld, L. T. Slatterya, Assessment of tungsten for use in the ITER plasma facing components, J. Nucl. Mater. 258 (1998) 308-312.

[2] G. Janeschitz, Plasma-wall interaction issues in ITER, J. Nucl. Mater. 290-293 (2001) 1-11.

[3] P. Norajitra, L.V. Boccaccini, A. Gervash, R. Giniyatulin, N. Holstein, T. Ihli, G. Janeschitz, W. Krauss, R. Kruessmann, V. Kuznetsov, A. Makhankov, I. Mazul, A. Moeslang, I. Ovchinnikov, M. Rieth, B. Zeep, Development of a helium-cooled divertor: material choice and technological studies, J. Nucl. Mater. 367-370 (2007) 1416-1421.

[4] H. Kurishita, S. Kobayashi, K. Nakai, T. Ogawa, A. Hasegawa, K. Abe, H. Arakawa, S. Matsuo, T. Takida, K. Takebe, M. Kawai, N. Yoshida, Development of ultra-fine grained W-(0.25-0.8)wt\%TiC and its superior resistance to neutron and $3 \mathrm{MeV}$ He-ion irradiations, J. Nucl. Mater. 377 (2008) 34-40.

[5] H. Kurishita, , H. Arakawa, S. Matsuo, T. Sakamoto, S. Kobayashi, K. Nakai, G. Pintsuk, J. Linke, S. Tsurekawa, V. Yardley, K. Tokunaga, T. Takida, M. Katoh, A. Ikegaya, Y. Ueda, M. Kawai, N. Yoshida, Development of Nanostructured Tungsten Based Materials Resistant to Recrystallization and/or Radiation Induced Embrittlement, Mater. Trans. 54(2013) 456-465.

[6] R. E. Nygren, R. Raffray, D. Whyte, et al., Making tungsten work, J. Nucl. Mater. 417 (2011) 451-456.

[7] Y. Kitsunai, H. Kurishita, H. Kayano, Y. Hiraoka, T. Igarashi, T. Takida, Microstructure and impact properties of ultra-fine grained tungsten alloys dispersed with TiC, J. Nucl. Mater 271-272 (1999) 423-428.

[8] P. L. Sun, E. K. Cerreta, J. F. Bingert, G. T. Gray III, M. F. Hundley, Enhanced tensile ductility through boundary structure engineering in ultrafine-grained aluminum, Mater. Sci. Eng. A 464 (2007) 343350.

[9] G. M. Cheng, W. W. Jian, W. Z. Xu, H. Yuan, P. C. Millett, Y. T. Zhu, Grain Size Effect on Deformation Mechanisms of Nanocrystalline bcc Metals, Math. Res. Lett. 1 (1) (2013) 26-31.

[10] H. Kurishita, Y. Amano, S. Kobayashi, K. Nakai, H. Arakawa, Y. Hiraoka, T. Takida, K. Takebe, H. Matsui, Development of ultra-fine grained $\mathrm{W}-\mathrm{TiC}$ and their mechanical properties for fusion applications, J. Nucl. Mater. 367-370 (2007) 1453.

[11] L. J. Kevskes, K. C. Cho, R. J. Dowding, B. E. Schuster, R. Z. Valiev, Q. Wei, Grain size engineering of bcc refractory metals: top-down and bottom-up application to tungsten, Mater. Sci. Eng. 467 (2007)33-34.

[12] R.Z. Valiev, R.K. Islamgaliev, I.V. Alexandrov, Bulk nanostructured materials from severe plastic deformation, Prog. Mater. Sci. 45 (2000) 103-189.

[13] Y. Zhang, A.V. Ganeev, J.T. Wang, J.Q. Liu, I.V. Alexandrov, Observations on the ductile-to-brittle transition in ultrafine-grained tungsten of commercial purity, Mater. Sci. Eng. A 503 (2009) 37-40. 
[14] Q. Wei, H. T. Zhang, B. E. Schuster, et al., Microstructure and mechanical properties of super-strong nanocrystalline tungsten processed by high-pressure torsion, Acta Mater. 54 (2006) 4079-4089.

[15] V. Piotter, B. Zeep, P. Norajitra, R. Ruprecht, A. von der Weth, J. Hausselt, Development of a powder metallurgy process for tungsten components, Fusion Eng. Des. 83 (2008) 1517-1520.

[16] M.A. Monge, M. A. Auger, T. Leguey, Y. Ortega, L.Bolzoni, E. Gordo, R. Pareja, Characterization of novel W alloys produced by HIP, J. Nucl. Mater. 386-388 (2009) 613-617.

[17] G. Prabhu, A. Chakraborty, B. Sarma, Microwave sintering of tungsten J. Refract. Met. Hard Mater. 27 (2009) 545-548.

[18] M. A. Yar, S. Wahlberg, H. Bergqvist, H. G. Salem, M. Johnsson, M. Muhammed, Spark plasma sintering of tungsten-yttrium oxide composites from chemically synthesized nanopowders and microstructural characterization, J. Nucl. Mater. 412 (2011) 227-232.

[19] R. Liu, Y. Zhou, T. Hao, T. Zhang, X. P. Wang, C. S. Liu, Q. F. Fang, Microwave synthesis and properties of fine-grained oxides dispersion strengthened tungsten, J. Nucl. Mater. 424 (2012) 171175.

[20] Y. Kim, K.H. Lee, E.P. Kim, D.I. Cheong, S.H. Hong, Fabrication of high temperature oxides dispersion strengthened tungsten composites by spark plasma sintering process Int. J. Refract. Met. Hard Mater. 27 (2009) 842-846.

[21] R. Liu, Z. M. Xie, Q. F. Fang, T. Zhang, X. P. Wang, T. Hao, C. S. Liu, Y. Dai, Nanostructured yttria dispersion-strengthened tungsten synthesized by sol-gel method, J. Alloys Compd. 657 (2016) 73-80.

[22] X. Ding, L. Luo, H. Chen, G. Luo, X. Zhu, X. Zan, J. Cheng, Y. Wu, Fabrication of W-1 wt.\% TiC composites by spark plasma sintering, Fusion Eng. Des. 92 (2015) 29-34

[23] S. Lang, Q. Yan, N. Sun, X. Zhang, L. Deng, Y. Wang, C. Ge, Microstructure, basic thermal-mechanical and Charpy impact properties of W-0.1 wt.\% TiC alloy via chemical method, J. Alloys Compd. 660 (2016) 184-192.

[24] D. Jiang, C. Ouyang, S. Liu, Mechanical properties of W-Ti alloys from first-principles calculations, Fusion Eng. Des. 106 (2016) 34-39.

[25] C. Chen, Y. Zeng, Influence of Ti content on synthesis and characteristics of W-Ti ODS alloy, J. Nucl. Mater. 469 (2016) 1-8.

[26] S. Wang, L. Luo, M. Zhao, X. Zan, X. Zhu, G. Luo, Y. Wu, Microstructure and properties of TINreinforced W-Ti alloys prepared by spark plasma sintering, Powder Technology 294 (2016) 301-306.

[27] R.M. German, E. Olevsky, Mapping the compaction and sintering response of tungsten-based materials into the nanoscale range, Int. J. Refract. Met. Hard Mater. 23 (2005) 294-300.

[28] J. L. Johnson, Progress in processing nanoscale refractory and hard metal. Proceedings of the 2008 Tungsten, Refractory \& Hard Materials VII, Washington, P.05.57-71.

[29] H. Wang, Z.Z. Fang, Sinter-ability of nanocrystalline tungsten powder, Int. J. Refract. Met. Hard Mater. 28 (2010) 312-316 
[30] X. Wang, Z. Z. Fang, M. Koopman, The relationship between the green density and as-sintered density of nano-tungsten compacts, Int. J. Refract. Met. Hard Mater. 53 (2015) 134-138.

[31] B.G. Butler, J. Lu, Z.Z. Fang, R. K. Rajamani. Production and characteristics of nanocrystalline tungsten carbide powder using a high energy dual-drive planetary mill. Int. J. Powder Metall. 2007;43(1):35-43.

[32] C. Ren, Z.Z. Fang, H. Zhang, M. Koopman, The study on low temperature sintering of nano-tungsten powders, submitted to Int. J. Refract. Met. Hard Mater.

[33] Z.Z. Fang, H. Wang, Densification and grain growth during sintering of nanosized particles, Int. Mater. Rev. 53 (2008) 326-52.

[34] G.L. Messing, M. Kumagai, Low-temperature sintering of alpha-alumina-seeded boehmite gels, Am. Ceram. Soc. Bull. 73 (1994) 88-91.

[35] M.F. Yan, W.W. Rhodes, Low temperature sintering of $\mathrm{TiO}_{2}$, Mater. Sci. Eng. 61 (1983) 59-66.

[36] R.M. German, J. Ma, X. Wang, E. Olevsky. Processing model for tungsten powders and extension to nanoscale size range, Powder Metall. 49 (2006) 19-27.

[37] J. Moulder, W. Stickle, P. Sobol, K. Bomben, 1995, Handbook of X-ray Photoelectron Spectroscopy, Physical Electronics, Inc., Eden Prairie, USA.

[38] M. Pichaud, M. Drechsler, A Field Emission Measurement of the Influence of Adsorption on Surface Self-Diffusion, Surface Sci. 32 (1972) 341-348 